\title{
0 percurso histórico da improvisação no ragtime e no choro
}

\author{
César Albino (UNESP/FMCG, São Paulo, SP) \\ cesaracalbino@yahoo.com.br
}

\author{
Sonia R. Albano de Lima (UNESP/FMCG, São Paulo, SP) \\ soniaalbano@uol.com.br
}

Resumo: 0 artigo teve como objetivo investigar em que medida a improvisação e a tradição oral permitiram a consolidação do ragtime e do choro em gêneros musicais com aceitação popular na virada do século XIX. A escolha concentrou-se nas semelhanças formais existentes entre ambos e nos caminhos percorridos por ambos para essa consolidação. A partir dos conceitos de territorialização e desterritorialização criados por Gilles Deleuze e Félix Guattari, incorporados à improvisação musical por Rogério Costa, verificamos o tipo de improvisação utilizado nesses dois gêneros. 0 relato histórico reafirma a ideia de D. Bailey de que a improvisação está sempre presente na criação de novos sistemas notacionais, gêneros e estilos musicais, ainda que nos processos de transmutação, ela saia de cena. 0 texto é parte da dissertação de mestrado defendida no IA-UNESP.

Palavras-chave: ragtime; choro; improvisação; música popular brasileira; música popular norte-americana.

\section{The historical path of improvisation in ragtime and choro}

Abstract: This study aims at investigating to what extent improvisation and oral tradition allowed for the consolidation of ragtime and choro into musical genres which became popular in the turning of the nineteenth century. The choice was concentrated on the formal similarities existing between both kinds of music and in the paths taken by both of them in their process of consolidation. As far as the concepts of territorialization and de-territorialization coined by Gilles Deleuze and Félix Guattari, and incorporated in musical improvisation by Rogério Costa, it was possible to verify the type of improvisation used in these two genres. Historically, it re-states D. Bailey's idea that improvisation is always present in the creation of new notational systems, genres and musical styles, even if it leaves the scene during the transmutation processes. This article derives from the first author's Master of Arts dissertation (IA-UNESP, Brazil).

Keywords: ragtime, choro; improvisation; Brazilian popular music; North-American popular music.

\section{1 - Ragtime, choro e improvisação: um recorte histórico}

No universo musical observa-se que as práticas improvisatórias sempre estiveram presentes na gênese das novas concepções que viriam a se tornar estilos ou na criação de novas modalidades notacionais, contribuindo, mesmo que de forma nebulosa, para o desenvolvimento das mesmas. Muitos relatos comprovam a presença da improvisação na criação de novos sistemas notacionais, gêneros e estilos musicais, no entanto, à medida que esses sistemas e gêneros se consolidavam, a improvisação saia de cena. Encontrar um ponto de equilibrio entre esses dois opostos parece ser a questão primordial a se trabalhar para a continuidade dessa prática performática.
Derek BAILEY(1993), no livro Improvisation: its nature and practice in music fala das dificuldades em se promover uma abordagem histórica da improvisação devido à natureza não-documental da atividade. Nessa publicação ele se reporta a Ernest Ferand para demonstrar a intensa presença dessa atividade em toda a história da música, mesmo em um terreno aparentemente inóspito como a Europa:

This joy in improvising while singing and playing is evident in almost all phases of music history. It was always a powerful force in the creation of new forms and every historical study that confines itself to the practical or theoretical sources that have come down to us is writing or in print, without taking into account the improvisational element in living musical practice, must of necessity present an incomplete, indeed a distorted picture. For there is scarcely a single field in music that has remained unaffected 
by improvisation, scarcely a single musical technique or form of composition that did not originate in improvisatory practice or was not essentially influenced by it. The whole history of the development of music is accompanied by manifestations of the drive to improvise (Ferand, 1961 Apud BAILEY, 1992, p.ix e x) ${ }^{1}$

Hoje, os jogos improvisatórios e algumas práticas improvisatórias têm sido empregados com certa frequência nos cursos de musicalização e iniciação musical com o intuito de incentivar a criatividade musical e a desenvoltura musical, entretanto, esses procedimentos não se caracterizam como práticas improvisatórias performáticas.

Na música erudita, a forte tradição escrita e o número pequeno de composições destinadas à improvisação impossibilitaram a proliferação dessa habilidade, fato que não ocorreu na música popular, pois nesse universo ela obteve níveis de aceitação plena.

Considerando-se a amplitude e a complexidade do assunto, foi necessário adotar uma linha de investigação que pesquisou de que forma a improvisação e a tradição oral foram contempladas em dois gêneros musicais provenientes dos EUA e do Brasil: o ragtime e o choro. Também foram verificadas as semelhanças formais existentes entre esses dois gêneros e o percurso trilhado por eles, que permitiu a consolidação de novos gêneros musicais, entre eles, o jazz, o bebop e outros.

Para o recorte histórico recorremos a um tipo específico de música executada no continente americano em meados do século XIX, que não se caracteriza nem como música folclórica, nem como música erudita, muito embora tenha sofrido suas influências. Esse tipo de música também difere da música popular mais recente, divulgada maciçamente nos meios de comunicação a partir da década de 1930 (cinema, rádio, disco e posteriormente a televisão), necessariamente cantada. Essa música contempla alguns gêneros basicamente instrumentais, semi-eruditos, no sentido estrito do termo, sofisticados, todos provenientes do continente americano: o tango instrumental argentino e uma diversidade de ritmos caribenhos conhecidos por salsa, identificados hoje por "música afrocaribeña", que apesar de ser tocada em vários países como Porto Rico, República Dominicana, Colômbia e Venezuela, tem sua origem em Cuba, o ragtime nos EUA e o choro no Brasil.

Esses estilos, gêneros, ou ainda idiomas, como têm sido recente chamados por alguns autores, têm em comum a peculiaridade de terem transcendido o aspecto ligeiro e dançante de suas origens, graças ao empenho de alguns compositores em elevá-los a um patamar mais erudito, possibilitando então a sua apreciação em ambientes mais propícios à audição, sem vínculos com a dança. Dentre esses autores podemos citar: Ernesto Nazareth, Duke Ellington, Astor Piazzolla, Tom Jobim e George Gershwin.

Henrique CAZES (1998, p.17) identifica-os com o termo música popular urbana, pelo forte vínculo estabelecido com determinadas cidades onde eles se originaram, mas a melhor definição para eles é fornecida por Geraldo SUZIGAN (1986, p.35), que se refere a essa música como o quarto gênero musical - a "Música das Américas" - uma música que oferece um alto grau de ineditismo harmônico e rítmico, improvisação e uma gramática própria. 0 autor sugere atenção das Instituições de ensino e dos educadores no estudo desse repertório, pela importância que o mesmo representa para a nossa cultura.

Esses estilos musicais, embora provenientes de vários países da América, apresentam características semelhantes, a saber: nasceram das tentativas locais de tocar a polca e outros tipos de danças europeias, mescladas ao sotaque do colonizador e à influência negra, gerando em pouco tempo, uma serie de "estilos híbridos" como polca-habanera, polca-schottisch, polca-lundu, polca-mazurca, que mais tarde, após um período de gestação que pode chegar a quase um século, seriam sintetizados em um "estilo" identificável com caracteristicas próprias, sofrendo, devido à origem, influências religiosas e culturais que the são determinantes (KIEFER, 1990, p.21). Originaram-se em cidades portuárias, em uma época de grande expansão urbana, principalmente, a partir da metade do século XIX (fim da escravatura e expansão do industrialismo). $\mathrm{Na}$ virada do século XIX, esses estilos já se encontravam consolidados e amplamente difundidos, agradando as diversas camadas da população (CAZES, 1998, p.17; COLLIER, 1995, p.9). Havia neles a presença efetiva das síncopes e uma variedade de conotações, mudanças de significado e uso frequente e impróprio de palavras, não apenas no campo da música popular, mas também na música erudita (KIEFER, 1990, p.24). Um exemplo dessa prática está presente em diversas partituras denominadas "tango" ou "tango brasileiro", hoje consideradas choros, o que implica em uma confusão terminológica, falta de informação, ou ainda, a "vergonha" de atribuir à música, o nome verdadeiro -"maxixe"-, uma dança de bordel. Empregar a palavra "tango" oferecia um risco menor para a época e passava a ideia de uma pseudo-erudição.

0 ragtime e o choro do início do século XX apresentam inúmeras semelhanças: ambos eram executados ao piano, muitas vezes pelos próprios compositores; havia a utilização efetiva das síncopes, muito comum na música africana, mescladas às características de danças oriundas da Europa, como é o caso da polca.

\section{2 - 0 ragtime}

0 ragtime, publicado pela primeira vez em 1895, tornouse conhecido nos EUA em pouco tempo. Em 1900 já era muito popular, encontrado nas partituras ${ }^{2}$, nos registros fonográficos, nos piano rolls ${ }^{3}$, executado nos teatros, bares e bordéis, impulsionando o mercado de partituras, de pianos e gravações (fonógrafos nessa fase) (SAGER, $2009)^{4}$. Tais considerações são relevantes ao que é conhecido como o ragtime clássico (classic rag), a fase áurea desse gênero, em que ele aparece estabilizado como estilo e escrito em notação tradicional, representado principalmente por Schott Joplin. No entanto, os termos 
associados ao ragtime têm definições inexatas, recebendo muitas vezes rótulos oportunistas de acordo com o momento e com os interesses comerciais da época.

São confundidos como ragtime os seguintes nomes, referentes a estilos, danças, canções, etc: cakewalk; marcha (caracteristica); two-steps; coon song (estilo vocal pré-ragtime popular até 1901, com letras cruéis e racistas frequentemente cantadas por cantores com o rosto maquiado de negro - uma das razões da má reputação atribuida ao ragtime); folk ragtime (de tradições orais); classical rag (o ragtime popularizado por Scott Joplin e James Scott por meio de partituras); fox-trot; novelty piano; stride piano; etc. (Jasen Apud SAGER, 2009).

É difícil definir com clareza o que é o ragtime. A definição que se segue é mais adequada ao ragtime clássico:

Ragtime - A genre of musical composition for the piano, generally in duple meter and containing a highly syncopated treble lead over a rhythmically steady bass. A ragtime composition is usually composed three or four contrasting sections or strains, each one being 16 or 32 measures in length. (SAGER, 2009) ${ }^{5}$

Essas soluções pianísticas agradavam muito ao público e foram posteriormente adaptadas para as bandas, em forma de arranjos. Arthur Pryor - assistente de regente e trombonista da famosa banda de John Philip Sousa, ajudou a difundir esse gênero musical na Europa, em 1900, quando para lá excursionou. Ele não apenas compôs a maior parte do material da banda, como também ensinou aos seus integrantes, a maneira de executar as sincopes de uma forma bem mais tranquila. Apesar do sucesso da banda, suas músicas eram publicadas apenas como adaptações para piano solo (SAGER, 2009).

A emoção do sincopado, muito presente no ragtime, geralmente causa no ouvinte, um sentimento de propulsão, de movimento, uma vontade de dançar. Esse deslocamento das batidas tem forte conotação com a música negra executada nas cidades que margeavam o rio Missouri, repleto de bares, bordéis e cabarés, lugares esses, onde um pianista com um repertório digno podia ter um nivel de vida decente (SAGER, 2009).
A síncope e outras soluções também sincopadas são muito comuns na música executada "de ouvido", encontrada em todo o Caribe e estados do sul dos EUA. A facilidade dos escravos em executá-la oralmente, foi com certeza determinante para a música desse continente. A síncope, porém, foi raramente encontrada em publicações americanas antes de 1880 .

Acredita-se que o ragtime tenha nascido da tentativa dos pianistas negros de adaptar ao piano, por meio da oralidade, aquilo que os músicos itinerantes tocavam no banjo. Em 1989, o ensaísta Lafcadio Hearn fez o seguinte comentário: "Did you ever hear negroes play the piano by ear?... They use the piano exactly like a banjo. It is good banjo-playing but no piano-playing"6 (Hearn Apud SAGER, 2009)

É difícil saber o que ocorreu anteriormente à fase escrita e consolidada do ragtime devido à falta de documentação. Não se pode explicar o ragtime a partir da primeira publicação, é preciso investigar como se chegou a ela. De nossa parte, podemos afirmar que a improvisação deve ter feito parte do processo que culminou nessas publicações, mas, nessa fase, ela já não fazia mais parte desse processo. 0 classic rag foi o tipo de ragtime que se perpetuou, devido justamente à escrita. 0 mesmo ocorreu com as famosas improvisações de Bach ao órgão. Elas só são conhecidas pelos relatos de seus contemporâneos, pois o que ficou para a posteridade são apenas suas obras escritas.

No início do século XX o ragtime exige para sua interpretação uma técnica apurada, alcançada apenas por pianistas com familiaridade em executar as síncopes. Apresentamos a seguir um exemplo didático (Ex.1) extraído do livro School of Ragtime: 6 Exercises for Piano, de Schott JOPLIN (1908, p.vii). Como se observa no exemplo, o estilo sincopado da melodia se contrapõe ao acompanhamento mais marcado (stride), o que resultou em um estilo balançado e movimentado.

0 ragtime, assim como o choro, foi escrito em compasso binário de $2 / 4$, como se escrevia comumente a polca. Os músicos de jazz, mais tarde, preferiram adotar o compas-

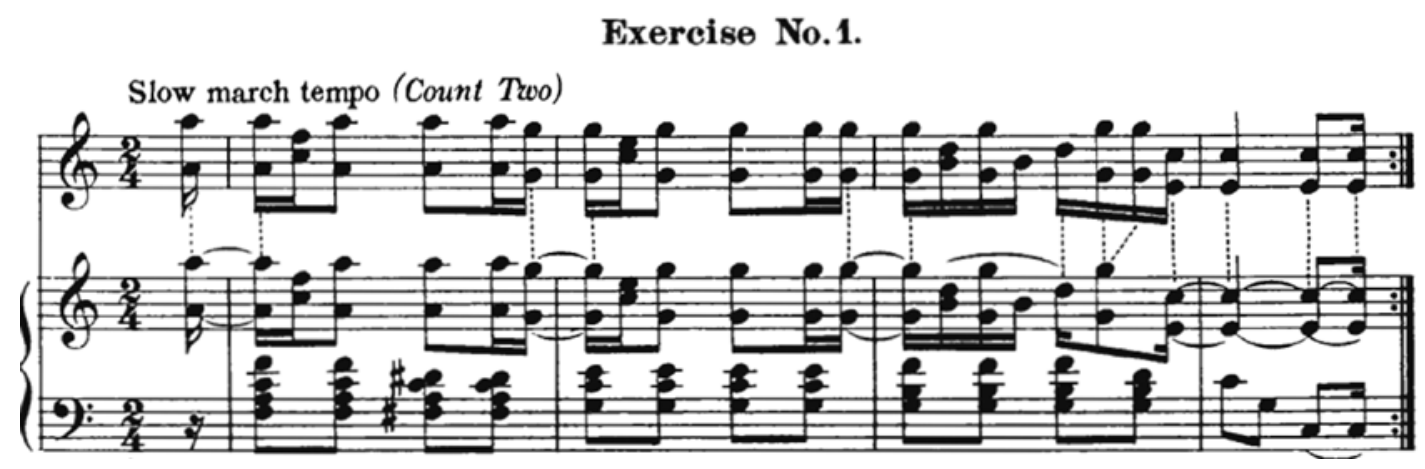

Ex.1 - School of Ragtime: 6 Exercises for Piano, de Schott Joplin: Exercício \# 1.0 autor, que foi também professor de piano e teoria musical, teve a preocupação de escrever a melodia em uma pauta anexa facilitando a visualização das antecipações 
so $4 / 4$ ou 2/2. No início tentou-se escrever o swing, onde o tempo é dividido em duas partes desiguais - a primeira nota tem uma duração maior que a segunda na razão de $2 / 3$ até $3 / 4$ do tempo. Utilizava-se então uma colcheia pontuada seguida de uma semínima (Ex.2).

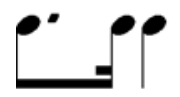

Ex.2 - Notação inicial do swing no jazz

Essa escrita não vingou. Os músicos preferiram escrever as colcheias de forma simples (50\% do seu valor), como mostra o Ex.3.

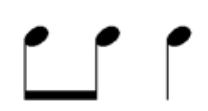

Ex.3 - Notação mais comum do swing no jazz

Que deveria ser interpretada da maneira mostrada no Ex.4.

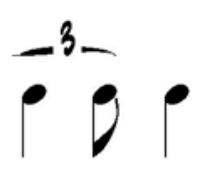

Ex.4 - Realização do swing no jazz

A tarefa da execução do swing fica a cargo do intérprete quando a indicação "swing" aparece como uma das instruções da partitura. 0 intérprete de jazz deve saber executá-las (tocar a primeira nota com maior duração que a segunda: quanto maior for a permutação, maior será o swing). Por isso Jacques RIZZO escreve na contracapa de seu livro Reading Jazz: "no jazz, aquilo que você vê não é o que você tem". Até hoje o intérprete de jazz tem presente essa regra.

0 ragtime foi um gênero musical importante até próximo de 1917 (ano da morte de Joplin). Posteriormente, o jazz executado desde o início do século, começa a superá-lo. 0 ragtime não se transformou no jazz, mas contribuiu para sua formação, sendo até hoje executado sem grandes inovações. Em 1920 seus intérpretes já estavam quase que esquecidos.

Apesar de os dois gêneros musicais (o jazz e o ragtime) terem sofrido influência direta da música negra, guardam certas diferenças. 0 swing é um dos principais diferenciais. Isso é bastante perceptível em uma interpretação jazzística e pode ser observado, por exemplo, nas gravações de Jelly Roll Morton interpretando classic rags e nas antológicas gravações do Modern Jazz Quartet quando interpreta Bach com roupagens jazzísticas. No ragtime a influência negra está concentrada na rítmica, no jazz ela se estende também para os recursos musicais verticais ${ }^{7}$ melódicos e harmônicos, muito comuns na música negra rural e religiosa americana do século XIX (spirituals e blues). Dessa maneira, portamentos, vibratos, glissandos e outras inflexões executadas com facilidade pela voz humana, podem ser reproduzidos pelos instrumentistas de sopro no jazz (MALSON \& BELLEST, 1989, p.14).

A não adoção dos elementos verticais da música negra no ragtime pode estar associada ao fato de ser uma música composta quase que essencialmente para o piano - um instrumento que não permite alterações sonoras significativas, pois dispõe de poucos recursos de dinâmica depois de ter suas notas articuladas. 0 mesmo não ocorre com os instrumentos de arco e de sopro, vez que eles podem produzir alterações propositais após a nota ser articulada, como crescendos, decrescendos, portamentos, vibratos, alterações de afinação, etc. Tais recursos foram utilizados somente no jazz.

Quanto aos aspectos harmônicos provindos da música negra, o melhor exemplo está no blues. Esse gênero musical, inicialmente cantado, é um gênero-forma inédito no Ocidente, geralmente com 12 compassos que utiliza os acordes que representam as funções básicas da tonalidade maior (I, IV e V) dispostos em ordem não convencional (a dominante antecede a subdominante no compasso 9). Com o tempo, agregaram-se a esses acordes, sétimas menores, conferindo à harmonia uma sonoridade peculiar proveniente da melodia. A melodia blues utiliza notas estranhas à harmonia: as blue notes [notas de blues], (b3, b5 e b7) levemente bemolizadas (pois não seguem o temperamento), sendo assim melhor interpretadas por instrumentos sem afinação fixa. 0 blues é mais uma forma do que um estilo, adotada pelos jazzistas, formando parte de seu repertório básico. Mais tarde, o blues foi utilizado por músicos de outros gêneros, como o rock. 0 grupo Beatles, por exemplo, surgiu de tentativas de tocar o blues que ouviam em Liverpool, cidade que mantém uma base militar americana, repleta de soldados negros que praticavam o blues na época.

A Rhapsody in Blue (1924) para piano e orquestra de George Gershwin (1898-1937) é um exemplo típico da utilização desses recursos musicais verticais. Gershwin, compositor americano, judeu, filho de russos, que morava no Brooklin - um bairro negro de New York - soube como poucos, explorar essa sonoridade americana. Já no início da obra, o compositor difunde no solo do clarinete a sonoridade jazzística. Os intérpretes atuais já incorporaram em suas execuções alguns desses recursos sonoros que não estão escritos de forma clara na partitura, como o glissando inicial, possivel apenas no clarinete, enriquecendo demais a orquestração, bem como alguns bends (desafinações para baixo) que o clarinete faz logo em seguida e uma série de recursos utilizados por músicos de jazz, como surdinas nos trompetes e trombones, trillos executados de uma forma diferenciada (shakes - um trillo característico do jazz em intervalo de terça menor, começando mais lento com acelerando). Muitos desses outros recursos verticais foram empregados na obra. Gershwin consegue incorporar o piano nesse ambiente sonoro, inclusive como instrumento solista. Na maior parte da peça, o piano soa como um piano clássico, em outros, o autor 
tenta explorar a sonoridade jazzística dentro de suas possibilidades $^{8}$, pois utiliza muitos elementos harmônicos e melódicos provindos do blues.

Outra diferença entre o jazz e o ragtime está no emprego da improvisação. Como já foi dito, possivelmente, o improviso fez parte da formação do ragtime, mas como o acesso se dá apenas por meio de partituras, fica praticamente impossivel um resgate de uma tentativa mais sólida nesse sentido, ficando apenas a suposição de que a improvisação tenha existido nesse estilo. Por outro lado, como o jazz praticamente nasce juntamente com o rádio e o disco ${ }^{9}$, a impressão é outra. Graças à tecnologia, 0 jazz pôde revitalizar o uso da improvisação na música popular do Ocidente, reacendendo uma ideia musical esquecida: a de que execução e criação musical não são atividades necessariamente separadas (BAILEY, 1993, p.48). Contrariando o senso comum, o jazz não é uma música totalmente improvisada. Há momentos em que um dos integrantes tem liberdade para criar suas próprias melodias (o momento do solo). Isso acontece sobre o chorus - a estrutura harmônica e rítmica de uma melodia que é utilizada como tema. A improvisação também acontece no acompanhamento, que não é escrito e deve ser executado sobre a mesma estrutura harmônica. Essa característica, entretanto, não esteve presente desde sua implantação:

Essas bandas inicias, portanto, desenvolveram-se da tradição de uma música que era, sem dúvida alguma, tocada em conjunto e não essencialmente improvisada. Os músicos podiam "ornamentar", mas na banda de marcha esperava-se que tocassem mais ou menos de acordo com uma linha preestabelecida; o interesse estava nas diferentes entradas dos instrumentos, sem contar, é claro, com o elemento ritmico. (COLLIER, 1995, p.36)
Só no final de 1920 o jazz tornou-se uma música para solista improvisador. Foram Sidney Bechet e Louis Armstrong os responsáveis por essa primeira grande transformação, ao criarem o solo improvisado. Como comenta Bob Wilber, enquanto Armstrong procurava o caminho, Bechet já o havia encontrado: "Falando de um modo geral, embora Sidney, no blues, improvisasse livremente, ele nem por isso deixava de seguir a forma do tema e variação, desenvolvendo com segurança um chorus de outro" (in COLLIER, 1995, p.45). Isso significa que Sidney estava criando melodias novas e ao mesmo tempo respeitando a estrutura rítmica e harmônica do chorus.

Um exemplo de chorus está na canção When the Saints Go Marching In, um hino evangélico tradicional americano tocado frequentemente em funerais de New Orleans (Ex.5). Foi muito executada por músicos de jazz, que utilizavam apenas a primeira parte (apresentada aqui) com uma conotação mais alegre. Os músicos solistas improvisavam, repetindo a estrutura quantas vezes desejassem. A mesma estrutura devia ser obedecida também pelos músicos encarregados do acompanhamento.

A eficiência dos solos sobre o chorus nessa fase do jazz ocorreu devido à utilização de sequências harmônicas simples, simétricas (com estruturas múltiplas de 4 compassos, geralmente 16 ou 12, como ocorre no blues) curtas e intuitivas. Tais estruturas possibilitavam aos músicos a criação de novas melodias independentes do tema e relacionadas à estrutura harmônica, afastandose, portanto, das variações sobre o tema, ou adornos e embelezamentos melódicos como se fazia anteriormente. Essa concepção possibilitou ao jazz um desenvolvi-

\section{WHEN THE SAINTS GO MARCHIN IN}

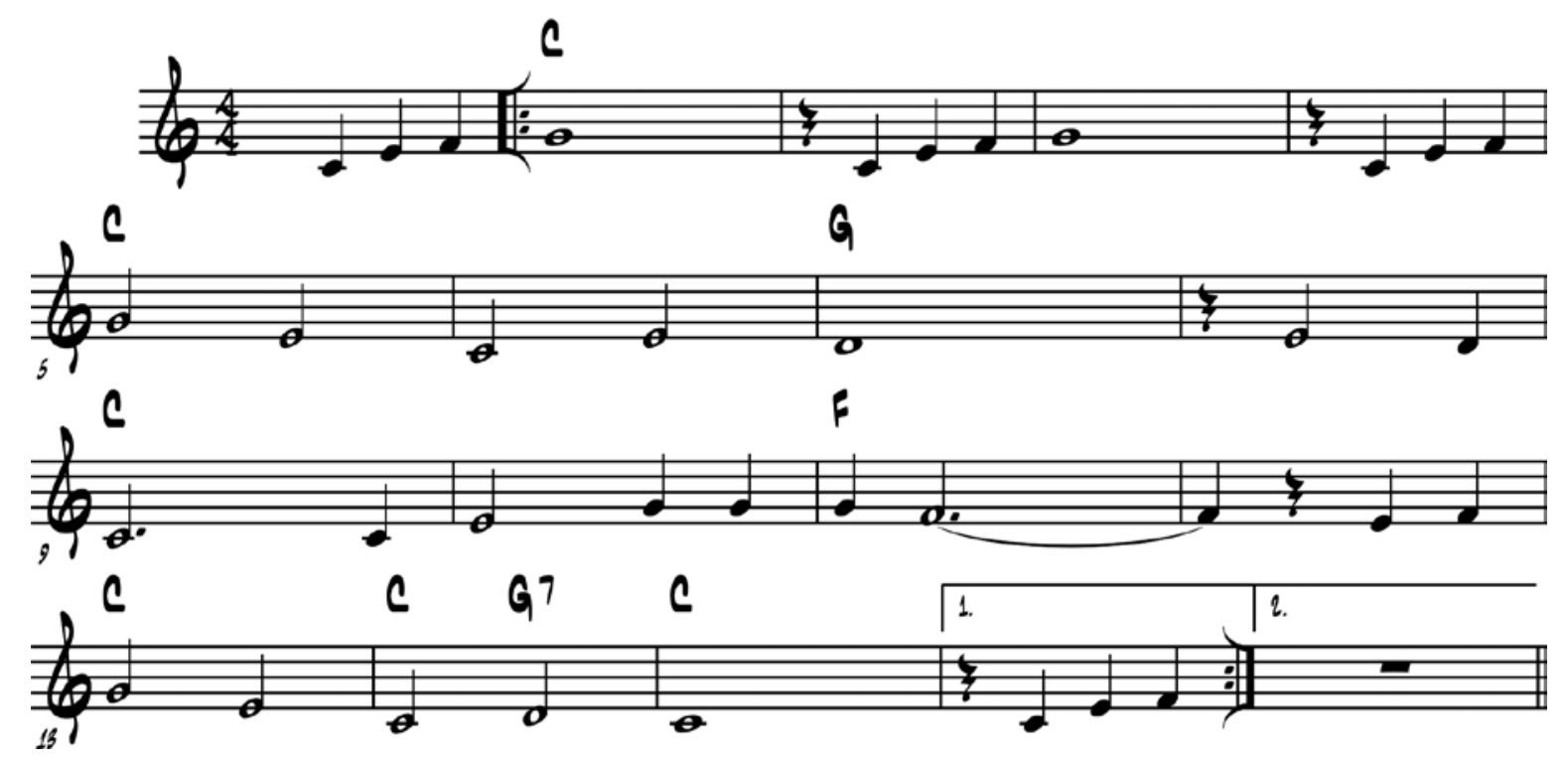

Ex.5 - When the Saints go Marchin In, Hino religioso tradicional, segue a estrutura rítmica e harmônica (cifrada) da canção de 16 compassos 
mento improvisacional baseado na harmonia, atingindo um alto grau de eficiência já na década de 40 . Foi por meio dessa concepção que músicos como Charlie Parker, John Coltrane, Miles Davis e tantos outros, puderam se desenvolver como improvisadores e elevar o jazz à categoria de música feita por improviso, mesmo que isso não fosse totalmente verdadeiro, mas que lhe conferiu 0 título de ter reintroduzido a improvisação no 0cidente, o que é uma verdade.

Outra característica importante que permitiu ao jazz se manter vivo, tendo a improvisação como principal vertente criativa, foi a sua incrivel capacidade de absorver influências externas sem se desestruturar. 0 jazz sofreu influências do ragtime, do blues, da música erudita, da música flamenca, da música brasileira, etc. e ao mesmo tempo em que foi influenciado, também influenciou, como ocorreu com a bossa nova. São muitas as oportunidades de ouvir músicos de jazz americanos tocando bossa nova com músicos brasileiros: João Gilberto \&t Stan Getz (1964), Tom Jobim \& Frank Sinatra (1967); Milton Nascimento \& Wayne Shorter (1975), etc. Nessas oportunidades, a bossa nova para esses músicos americanos se desenvolveu como um tipo de jazz (brazilian jazz), assim como outras possibilidades: latin jazz; gipsy jazz; free jazz; cool jazz. Ao ponto de podermos encontrar composições típicas da bossa nova compostas por músicos de jazz americanos, como Pensativa (1962) de Clare Fischer e Alone in the morning (1994) de Joshua Redman. Isso só foi possível com a adoção do chorus, que delimita claramente o campo de ação do improvisador, da forma como é entendida no jazz.

0 jazz experimentou mais de uma vez o rompimento com a o passado, buscando novos horizontes. A primeira vez foi por volta de 1930, situação já comentada, com a invenção dos solos, a segunda com o bebop (meados de 1940) e a terceira, com o free jazz (1960), o que demonstra a sua forte vocação para a renovação.

0 bebop praticado a partir da segunda metade da década de 1940 constituiu-se em um ato de rebeldia dos jazzistas contra o jazz orquestrado, arranjado e escrito, tocado pelas orquestras de dança no entre guerras (orquestras de swing). Nessas formações orquestrais, os músicos tinham cada vez menos espaço para improvisar. Uma das questões fundamentais do bebop foi o ressurgimento da improvisação nos moldes introduzidos por Bechet no final dos anos 1930. Sua execução em andamentos rapidíssimos, com harmonias mais complexas, revolucionou a forma de executar o jazz, implicando em sua modernização. Nenhum músico ao tocar o bebop poderia fazê-lo da forma como era executado o swing, pois as antigas soluções simplesmente não funcionavam nos andamentos do bebop - muito mais rápido. A atitude de músicos como Thelonious Monk, Charlie Parker e Dizzy Gillespie, conhecidos por "inventar" o bebop (HOBSBAWM, 1989, p.365), reiterou a importância da utilização da improvisação nessa música, impedindo que a atividade viesse a desaparecer, como sempre ocorreu no desenvolvimento musical de formas, estilos e sistemas musicais onde um dia a improvisação esteve presente.

0 terceiro momento revolucionário do jazz, conhecido como free jazz, trouxe consigo um intenso desejo de renovação, uma proposta radical que teve como lema a negação das leis, das regras idiomáticas e da gramática dos sistemas. Tentou romper com idiomas, clichês e gestos, rumo à liberdade total, mas ainda assim, continuou jazz, pois manteve aspectos comuns ao gênero executado por seus antecedentes, não conseguindo se desvincular dessas características. Como exemplos de músicos que adotaram essa linha avant-gard citamos: Ornette Coleman, Archie Shepp, Eric Dolphy, Don Cherry e posteriormente John Coltrane, Charles Mingus e Cecil Taylor (HOBSBAWM, 2008, p.12).

Após essa experiência radical, a improvisação continuou seu curso básico dentro dos moldes introduzidos por Bechet, sempre considerando o respeito à improvisação e ao improvisador, sendo esse o foco dessa maneira de tocar, que independente dos momentos de inovação-tradiçãorenovação, manteve a improvisação em um fluxo de energia constante e renovador, quase como um ideal.

\section{3 - 0 Choro}

A improvisação na música popular brasileira se desenvolveu de forma bem diferente da verificada nos EUA, apesar das características semelhantes verificadas nos principais estilos desses dois paises antes do século XX. Podemos dizer que as influências religiosas e culturais foram determinantes nessas diferenças. A religião predominante nos EUA é a protestante, não tão permissiva como a católica, predominante na América Latina. Nos EUA, o negro deveria cantar os hinos evangélicos, em língua inglesa, não podendo, por exemplo, dançar, tocar um tambor, ou falar seu idioma nativo. Isso também ocorreu na América Latina, mas sem tanta restrição. Dessa maneira a música negra da América Latina é basicamente alegre e dançante, já o blues americano é arrastado, pesado, chorado, um lamento.

0 principal gênero popular no Brasil foi o choro, que apresenta uma história de 130 anos, um periodo de tempo considerável para nossa cultura. Surgiu no início dos anos 1870, antes do ragtime, e assim como outros gêneros sul-americanos, teve raízes na forma de executar a polca (TINHORÃO, 1991, p.103).

Assim como ocorreu nos EUA e Caribe, a influência da música negra na música popular brasileira se fez presente basicamente na rítmica, utilizando muito pouco dos recursos verticais, tão familiares ao jazz e apesar de sua origem dançante (polca), o choro constituiu-se em uma música instrumental para ser ouvida. Contou para essa tarefa com músicos consagrados como: Antonio da Silva Callado, Ernesto Nazareth, Chiquinha Gonzaga, dentre outros. 
Da mesma maneira como ocorreu no ragtime, são encontrados no Brasil, muitos compositores que executavam seus próprios choros, mesmo que ainda não recebessem tal rótulo. Muitos músicos de choro provinham ainda de bandas musicais, comuns em eventos cívicos e religiosos. Essas bandas revelaram-se boas formadoras de músicos e maestros, supõe-se, portanto, que esses músicos sabiam ler partituras (CAZES, 1995, p.33; TINHORÃO, 1997, p.118).

Enquanto o ragtime teve sua produção basicamente dirigida para o piano, no choro as execuções se desenvolveram em conjuntos típicos formados por flauta, cavaquinho, pandeiro e violão - as "rodas de choro". Só depois de algum tempo o choro foi adaptado para o piano, exigindo ambientes mais aristocráticos. 0 choro para piano teve como ícone a figura de Ernesto Nazareth (1863-1934), que preferiu adotar a denominação "tango brasileiro" para suas peças, por rejeitar a ideia de que sua música pudesse ser considerada "popular".

Nas rodas de choro participavam tanto intérpretes alfabetizados musicalmente como músicos que "tocavam de ouvido". Antonio da Silva Calado, considerado um dos maiores flautistas de seu tempo, era o único que sabia ler partituras em seu grupo de choro:

Ficou então constituído o mais original agrupamento reduzido do nosso país - 0 Choro, de Calado. Constava ele desde a sua origem de um instrumento solista, dois violões e um cavaquinho, onde somente um dos componentes sabia ler a música escrita: todos os demais deviam ser improvisadores do acompanhamento harmônico. (Siqueira, Apud TINHORÃO, 1991, p.104)
Tanto a oralidade, como a improvisação, foram componentes importantes no desenvolvimento do choro. Comumente, o que se executava musicalmente não era o que estava escrito na partitura. É o típico caso de uma música que estava sendo criada e modificada ao mesmo tempo em que era executada. A notação musical transcrita servia apenas de guia para os solistas, da mesma forma como ocorreu com a música executada no período Barroco.

Recentemente tem surgido uma série de publicações visando resgatar o material sonoro deixado pelo choro, de forma fidedigna. As dificuldades têm sido enormes, como nos conta a pianista Maria José CARRASQUEIRA na recente reedição da obra do flautista Pattápio Silva:

\footnotetext{
É de suma importância ressaltar que nem sempre Pattápio foi fiel ao texto impresso das obras que gravou, mesmo porque, suas composições ainda não estavam editadas nessa época. Nosso propósito é aclarar somente as diferenças mais significativas, reiterando seu caráter inventivo de músico-criador, em interpretações surpreendentes para um jovem músico de apenas 22 anos de idade (CARRASQUEIRA, 2001, p.14).
}

Como no ragtime, a presença das síncopes no choro é predominante, entretanto, aqui elas aparecem também no acompanhamento. Observe a presença delas tanto na mão direita de Odeon de Ernesto Nazareth (Ex.6), como na esquerda, diferentemente do que ocorre no ragtime.

0 choro, como o ragtime, utilizou preferencialmente a forma rondó "ABACA" com modulações - forma muito comum em músicas realizadas por bandas e piano no século XIX. Essa forma se mostrou bastante inapropriada à
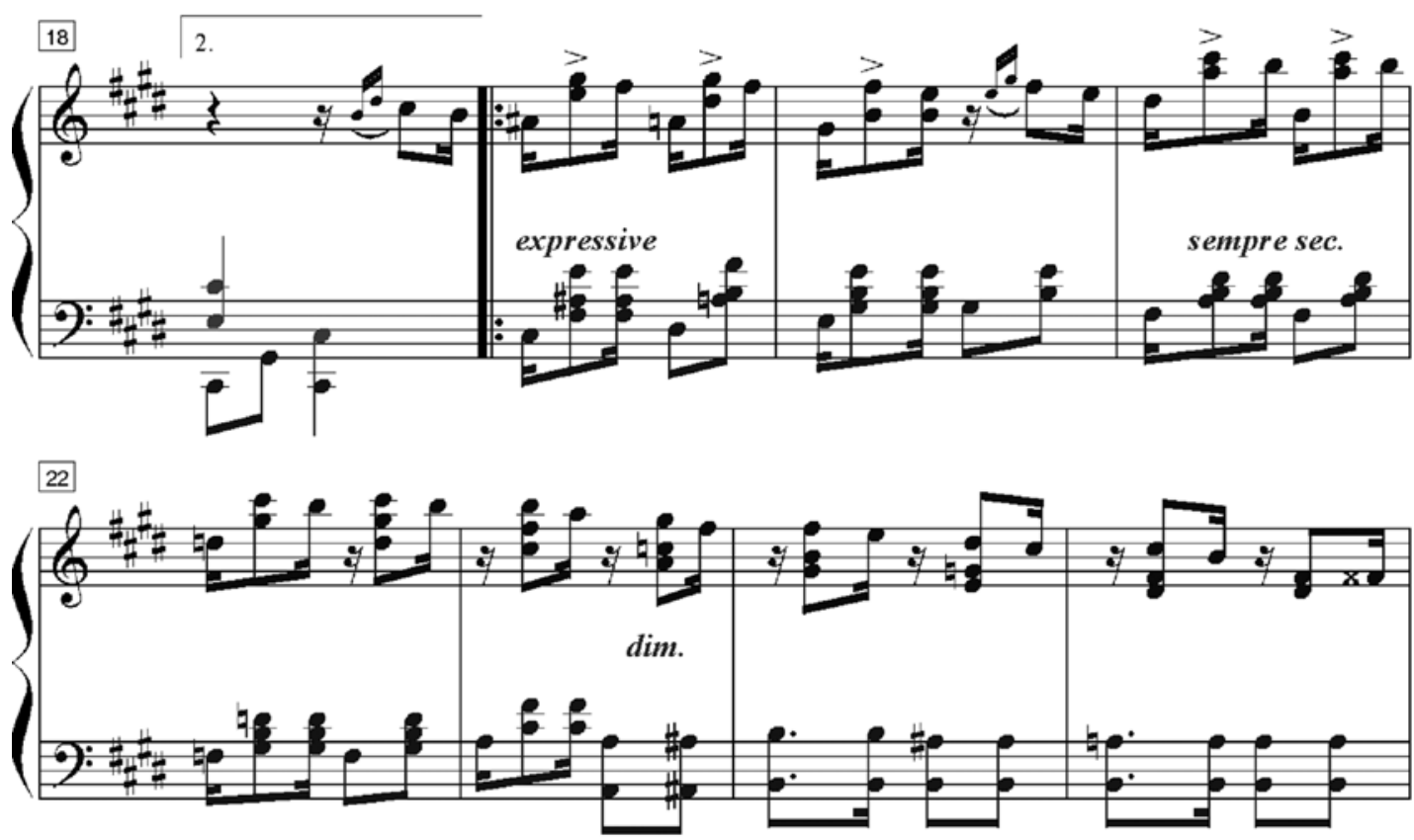

Ex.6 - Utilização de síncopes em Odeon (c.18-25) de Ernesto Nazareth. 
improvisação como a utilizada pelo jazz no final da década de 1930 como explica Paulo SÁ.

Sua forma tradicionalmente ternária com cinco sessões ABACA, não propicia o mesmo tipo de improviso realizado no jazz, isto é, o chorão não se propõe a expor um tema e depois improvisá-lo na íntegra, porque sua música já é suficientemente rica em sua melodia, e além disso os trechos a serem improvisados ficam a critério do chorão e não prescindem de um momento predeterminado (SÁ, 2000, p.67).

Começa a ficar claro que o foco do chorão está na melodia e não na harmonia. Assim, o desenvolvimento da improvisação no choro não se deu como no jazz. "[...] faz parte do choro entender o chamado improviso através de um pensamento melódico-improvisatório baseado na própria melodia chorona que está sendo executada"(SÁ, 2000, p.67). Mais adiante Paulo Sá declara:

No caso do choro não existe um improviso nascido de divagações, isto é, não se espera do músico chorão que ele simplesmente improvise melodias que porventura venham à sua mente ou a seus dedos, compondo assim uma espécie de choro instantâneo. 0 improviso chorão nasce de um choro previamente concebido, portanto, ele possui um referencial que será também o seu limite. Mas tendo em vista que o tipo de improviso que se costuma fazer no choro é fundamentado na melodia, o que ocorre, portanto, é que esta é permanentemente lembrada ou citada durante a improvisação. Trata-se por conseguinte de uma variação melódica. [...] No entanto, o problema maior da conceituação dessa maneira chorona de improvisar está justamente no fato que as variações realizadas são também improvisadas. [...] a aplicação de variações melódicas memorizadas em momentos predeterminados implica na ausência de um improviso [...] embora na compreensão de alguns chorões estas variações memorizadas continuem a ser o que eles chamam de improviso (SÁ, 2000, p.69).

Fica claro ainda que o conceito de improviso no choro é um tanto nebuloso ou impreciso, mesmo entre alguns chorões (SÁ, 2000, p.66). Ou seja, muitos músicos dizem estar improvisando sem, no entanto, estarem.

Nas gravações existentes, observa-se recorrentemente que o músico que executa a melodia (músico solista), não foge muito dela, pois tais modificações seriam "perseguidas" facilmente pelos habilidosos e intuitivos músicos acompanhantes. Esse pensamento norteou grandes músicos, como Callado, Pixinguinha, Pattápio e Jacob do Bandolim. 0 flautista Daniel DALAROSSA descreve o que acontece em uma roda de choro no que diz respeito à improvisação:

Numa roda de choro, uma caracteristica importante é a liberdade dada ao solista para conferir sua própria interpretação à música que executa, não tendo necessariamente de seguir a partitura em todos seus detalhes.

Isso faz parte do espirito do Choro. 0 Chorão interpreta um dado Choro utilizando ornamentos (trilos e mordentes são muito comuns) previamente inseridos na frase musical, ou cria frases de acordo com sua personalidade, ensaiando tudo isso previamente. 0 Chorão também pode simplesmente improvisar, criando frases não existentes na partitura original.

Com muita frequência, o Chorão aperfeiçoa uma dada improvisação ou criação já ensaiada e tocada muitas vezes em sua vida musical, até incorporar a frase em seu repertório e consagrá-la como sua "marca-registrada" (DALAROSSA, 2008, p.17).
Expressões "inseridas previamente" e "uma improvisação já ensaiada" estão em desacordo com a concepção de improvisação como a oferecida, por exemplo, pelo Dicionário Groves de Música: "a criação de uma obra musical, ou de sua forma final, à medida que está sendo executada". Elas não trazem a ideia fundamental da improvisação que é a criação no momento da execução. Outros dicionários dão definições semelhantes (OXFORD, 1997; HARVARD DICTIONARY OF MUSIC, 1969; DICCIONARIO DE LA MÚSICA $\angle A B O R$, 1954). No entanto, tais práticas são empregadas e entendidas como sendo improvisação por parte dos músicos de choro, equivocadamente, no nosso modo de entender. 0 que ocorre de fato é que a tradição pede que o músico ao tocar um choro, não respeite plenamente a partitura, nesse aspecto, alguns improvisam efetivamente e outros, menos capazes de improvisar, aplicam variações "previamente ensaiadas". Porém, é no acompanhamento do choro que a improvisação ocorre em maior grau, mantendo-se em um nivel semelhante ao que deve ter sido no passado. Em cada repetição, em cada nova execução, percebe-se que esses acompanhamentos são executados de maneira diversa e espontânea. Apesar das restrições formais, o choro tem mantido a presença da improvisação, sendo, ainda hoje, o gênero onde mais se improvisa e onde mais se respeita o improvisador no Brasil.

Da mesma forma que o ragtime, a partir de 1930 o choro cai no esquecimento, apesar dos 60 anos anteriores de glória, perdendo espaço para gêneros cantados nas rádios, provenientes do samba (samba-canção, samba-exaltação, etc.), gêneros que tiveram como base o próprio choro. Poucas intervenções modificaram esse quadro, como a de Jacob do Bandolin, um dos grandes nomes da música popular brasileira. 0 choro virou uma música de "velhos" e teve de esperar até a década de 1970, quando ocorreu um verdadeiro revival sendo redescoberto por jovens músicos do Rio de Janeiro e Brasília. É hoje uma música muito executada e estudada nesses centros, contando com algumas inovações, ainda tímidas no que se refere à improvisação.

Esse é um componente que se quer preservar. Nos atuais intérpretes de choro, percebe-se a tentativa de encontrar novos espaços para a improvisação. No entanto, é difícil desvencilhar-se das estruturas formais do passado, produto dos 130 anos de tradição. É preciso encontrar uma forma de romper com tais amarras caso se queira avançar e manter a improvisação em um patamar mais alto de utilização nesse gênero tão interessante e tão genuinamente brasileiro de tocar. Fazer o que fez o jazz, se autorevolucionando, mas não da forma como ele o fez, tendo em vista que as soluções encontradas são incompativeis com a forma de pensar do músico de choro (melodia versus harmonia). Há de se encontrar uma solução inovadora que possa partir da própria improvisação, mas para isso seria necessário dar mais espaço e importância a ela.

Rogério Costa, baseado no pensamento de Deleuze, dá uma explicação para o fenômeno da improvisação, que pode por sua vez explicar porque o choro reluta em inovar: em um primeiro momento criam-se os territórios. 
Isso se dá por meio da repetição periódica dos componentes, criando membranas que o separam do mundo exterior. Nesse início, existe apenas o plano, as matérias e as energias não formadas. Ainda não há qualidade nem permanência para se tornar forma. Não há ainda um discurso analítico, sistematizador. Só há virtualidades sendo atualizadas. Em algum momento se atinge a "maturidade" (o segundo momento) do território com suas referências históricas e geográficas, possibilitando o idioma (o estilo), a expressão e a improvisação idiomática, que depois de estabelecidos, oferecem resistência às novas configurações. Por isso as mudanças são lentas e graduais. Os ritornellos (as tais repetições periódicas), as redundâncias e tudo o que dá identidade e qualidade à performance, acabam gerando membranas tão espessas que acabam impossibilitando o ritmo e a produção. Surge então uma fórmula abstrata, um sistema de reprodução, uma superfície de captura e uma gramática, possibilitando a sistematização e a criação de uma escola a ser imitada (parte abstrata do idioma) (COSTA, 2003, p.75-6).

Nessa territorialização, um ser vivo estabelece suas membranas, seus territórios, seus limites, sempre a partir de procedimentos repetitivos. Porém, após a estabilização do território (o segundo momento), é preciso que se abram poros nas membranas constituidas e ai, o ritornelo apresenta por sua vez um caráter dinâmico e não estático, de equilibrio entre a atitude que visa a manutenção da identidade de cada meio em manter tal membrana e uma atitude inversa que visa sua diluição. Em outras palavras, da mesma forma que um plano tende a se territorializar, tende também a se desterritorializar, em um processo continuo e alternado que depende da fluência do ritmo entre os diversos meios e da permeabilidade da membrana de cada um (COSTA, 2003, p.66).

Num terceiro momento, partem linhas de fuga por dentro do território (pequenas escapadas, indisciplinas, que acontecem em direção ao caos: a viagem de Colombo) que vão lentamente desestruturando o idioma (desterritorialização), e também as infiltrações do caos nos sistemas fechados (as invasões). Aqui, há uma volta da produção em um processo que o autor denomina de bricolagem (raspagem), onde acontecem as revoluções, as transformações a partir do que existia. Assim nasceu o Bebop.

Sibila GODOY, também baseada em Deleuze, reflete processo semelhante vivido pelo músico Egberto Gismonti em suas renovações por meio da improvisação:

Na improvisação, num primeiro momento Gismonti se depara com o caos, para, a seguir, selecionar elementos heterogêneos e organizá-los num "espaço-limitado" onde ganham forma e autonomia expressiva. Colocado numa situação em que é obrigado a funcionar a partir do caos e depois numa organização do caos, o compositor se abre para forças futuras, arrisca-se improvisando. Arriscando-se, descobre potências e essas potências é que vão fazendo suas transformações ou o começo de transformações. Nesse processo de improvisação em que Gismonti se liberta das formas de compreensão de mundo anteriores, consolida-se um novo território (GODOY, 2000, p.58).

\section{Considerações finais}

Os dois primeiros momentos (os dois primeiros ritornelos de Deleuze) descritos acima ocorreram no choro e no ragtime: nasceram do caos, consolidaram-se como estilos, criaram uma gramática e uma sistemática própria, criaram suas membranas separando-os do caos. Quanto ao terceiro momento (terceiro ritornelo de Deleuze), o que de fato ocorreu em relação a esses dois idiomas?

No ragtime, não houve o terceiro momento e o estilo tornou-se "clássico", cristalizado, com membranas fechadas para o novo, preferindo ser perpetuado nas partituras que ficaram para a posteridade. Nesse instante, nasce 0 jazz (seria ele o terceiro momento renovador?), que por sua vez, recusou o conformismo, mantendo sempre que possivel as membranas abertas para outras possibilidades inovadoras e restauradoras, tendo a improvisação como importante ferramenta de experimentação.

Podemos dizer, seguindo o mesmo raciocínio, que o choro e os músicos de choro criaram membranas tão espessas que impossibilitaram a existência do terceiro momento descrito acima, preferindo permanecer dentro do conforto oferecido pela tradição a se arriscar por novos horizontes. No entanto, temos ouvido cada vez mais intérpretes e músicos de choro buscando inovações, adotando a improvisação. Esperamos que essas intervenções permitam essa renovação que ainda não ocorreu nesse gênero musical. Permitir espaço para improvisação significa aqui renovação, revolução, como ocorreu no início, na gênese dos novos estilos, inclusive no choro. Precisamos ainda considerar, como mostra a história, que a improvisação é o meio pelo qual essas novas descobertas serão conhecidas. É por meio dela que se consegue aglutinar ideias aparentemente desconexas em soluções criativas e originais que possibilitam a descoberta de um caminho novo, original.

0 choro tenta manter a improvisação em seu escopo, como se disso dependesse sua própria vida, talvez sabendo que se ela desaparecer, ele também desaparecerá, cristalizando-se em uma forma por demais endurecida como ocorreu com o ragtime. A solução dos músicos de jazz, que no início também eram músicos de ragtime, foi manter a todo custo a vertente improvisacional, transformando o ragtime, ou qualquer outra influência em jazz - uma forma libertária de tocar. Puderam, por meio dessa ideologia, alcançar um alto grau de desenvolvimento nas questões improvisatórias, que foram solucionadas pelas próprias possibilidades da habilidade. Curiosamente, 0 jazz consegue manter-se vivo e inovador, sendo o gênero mais influente e desenvolvido no uso dessa habilidade. Esperamos também que o choro encontre soluções ousadas e personalizadas que permitam o desenvolvimento da 
improvisação em níveis mais acentuados. Sabemos, como mostra a história, que essas soluções serão encontradas por meio da própria improvisação, assim, quanto maiores forem as oportunidades, maiores serão as possibilidades de inovação. Resta acrescentar ainda o papel da educa- ção nesse processo. É preciso estudar e sistematizar todo esse conhecimento adquirido em 130 anos de tradição, para que se possa então ter coragem e fundamentação para transgredir a ordem estabelecida, saindo em busca do terceiro momento inovador levantado por Deleuze.

\section{Referências}

ANÔNIMO. When the Saints go Marchin In. Partitura digitalizada em Finale.

BAILEY, Derek. Improvisation: its nature and practice in music. USA: Da Capo Press, 1993.

BERLIN, Edward A. A biography of Scott Joplin. Scott Joplin International Ragtime Foundation. 1998. in http://www.scottjoplin.org/biography.htm acessado em 28/04/2009.

CARRASQUEIRA, Maria José (coordenação). O livro de Pattápio Silva: obra completa para flauta e piano. São Paulo: Irmãos Vitale, 2001.

CAZES, Henrique. O Choro: do quintal ao municipal. São Paulo: Ed. 34, 1998.

COLLIER, James Lincoln. Jazz: a autêntica música americana; tradução Carlos Sussekind, Teresa Resende da Costa. Rio de Janeiro: Jorge Zahar Ed., 1995.

COSTA, Rogério Luiz Moraes. Improvisação livre e idiomática: a máquina e o mecanismo, o que deve comunicar a música? In: Música Hodie; Revista do programa de Pós-Graduação Stricto-Senso da Escola de Música e Artes Cênicas da Universidade Federal de Goiás. Vol. 2 (n. 1/2, 2002): UFG, 2002.

COSTA, Rogério Luiz Moraes. 0 músico enquanto meio e os territórios da livre improvisação. Tese apresentada ao curso de Doutorado do Programa de Comunicação e Semiótica da PUC-SP, 2003.

DALAROSSA, Daniel. Uma palavra sobre interpretação e improvisação: In Ernesto Nazareth: clássicos do Choro brasileiro, vol. 1. São Paulo: Global Choro Music Corporation, 2007.

DELEUZE, Gilles: GUATARI, Félix. 1837 - A cerca do ritornelo. In mil platôs, vol. 4. Tradução Suely Rolnik. São Paulo: Ed. 34, 1997.

DICCIONARIO DE LA MUSICA LABOR. Barcelona: Editorial Labor, 1954.

DICIONÁRIO ELETRÔNICO HOUAISS. Versão 1.0. Editora Objetiva Ltda., 2001.

DICIONÁRIO GROVE DE MÚSICA. Edição concisa. Rio de Janeiro: Jorge Zahar Ed., 1994

GODOY, Sibila. Dança das cabeças: a trajetória musical de Egberto Gismoni. In Pesquisa e Música. Revista do Conservatório Brasileiro de Música, Volume 5, Número 1, p.58-65, 2000.

HOBSBAWM, Eric J. História social do jazz. Tradução Ângela Noronha. São Paulo: Editora Paz e Terra S/A, 1989.

$<<$ http://en.wikipedia.org/wiki/Piano_roll>> acessado em 22/04/2009.

<<http://lcweb2.loc.gov/diglib/ihas/loc.natlib.ihas.200035811/default.html>> acessado em 19/10/2009.

JOPLIN, Scott. School of ragtime: exercises for piano by Scott Joplin. New York: Scott Joplin, 1908.

KIEFER, Bruno. Música e dança popular: sua influência na música erudita. Porto Alegre: Editora Movimento, 1990.

MALSON, Lucien: BELLEST, Christian. Jazz. Tradução Paulo Anderson Fernandes Dias. Campinas: Papirus, 1989.

NAZARETH, Ernesto. Odeon. Partitura digitalizada em Finale.

RIZZO, Jacques. Reading jazz: the new method for learning to read written jazz music. Miami: Belwin, 1989.

SÁ, Paulo. 0 Improviso do choro. In Pesquisa e Música. Revista do Conservatório Brasileiro de Música, Volume 5, Número 1, p.66-70, 2000.

SAGER, David. A History of Ragtime. in: << http://lcweb2.loc.gov/diglib/ihas/loc.natlib.ihas. 200035811/default.html>> acessado em 4/10/2009.

SUZIGAN, Geraldo: SUZIGAN, Maria Lúcia. Educação musical: um fator preponderante na construção do ser. São Paulo: CLR Balieiro, 1986. Coleção ensinando-aprendendo, aprendendo ensinando. Cadernos brasileiros de educação.

THE NEW HARVARD DICTIONAY OF MUSIC. USA, Harvard University Press Reference Library, 1969. THE OXFORD COMPANION TO MUSIC: New York: Oxford University Press, 1997.

TINHORÃO, José Ramos. Música popular: um tema em debate. São Paulo: Editora 34 Ltda. 1997, 3a edição. . Pequena história da música popular brasileira: da modinha à lambada. São Paulo: Art Editora Ltda., 1991. 


\section{Notas}

1 Tradução: Essa alegria de improvisar enquanto se canta e se toca um instrumento é evidente em quase todas as fases da história da música. Essa foi sempre uma força poderosa na criação de novas formas, e todo o estudo histórico que se limita à prática ou às fontes teóricas que nos foram deixadas de forma escrita ou impressa, sem levar em conta o elemento de improvisação e a vivência da prática musical, deve ser considerado necessariamente como algo incompleto, certamente um retrato distorcido. Pois quase não há um único campo na música que não tenha sido afetado pela improvisação, nem uma única técnica musical ou forma de composição que não tenha tido origem na prática improvisadora, nem que não tenha sido influenciado essencialmente por ela. Toda a história do desenvolvimento da música é acompanhada por manifestações de impulsos para se improvisar.

2 A venda de partituras para o piano foi sempre um aspecto muito relevante nesses gêneros e comprova que nessa fase a oralidade e a improvisação já não estavam mais presentes no ragtime. Em 1914 a partitura do rag "Maple Leaf Rag", de Schott Joplin, publicada pela primeira vez em 1899, atinge a marca de um milhão de cópias (SAGER, 200?).

3 Um piano roll é um rolo de papel com perfurações acionado por um dispositivo conhecido como "bar tracker". A posição e tamanho das perfurações

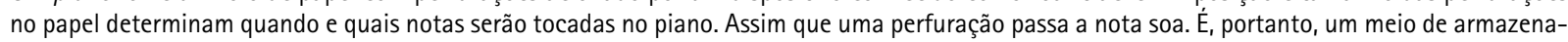
mento musical, utilizado para gravar, operar ou reproduzir um piano. Foi o primeiro meio que permitiu copiar industrialmente uma execução musical. Tiveram uma produção em massa a partir de 1896. Hoje eles foram substituídos por arquivos MIDI, uma forma moderna de armazenar e controlar os dados de uma execução, que podem por sua vez acionar via eletrônica, o mecanismo de um piano. Muitos softwares de música apresentam uma interface inspirada no piano roll, podendo ser muito mais precisa que a notação musical tradicional. (http://en.wikipedia.org/wiki/Piano_roll)

40 texto encontra-se no site da Biblioteca do Congresso Americano << http://lcweb2.loc.gov/ diglib/ihas/loc.natlib.ihas. 200035811/default.html>> acesso em 19 de outubro de 2009. Nele não consta a data exata de sua publicação. Sabemos apenas que é posterior ao ano 2000, daí a não inclusão do ano neste texto.

5 Tradução: Ragtime: um estilo de composição musical para o piano, geralmente em compasso binário que contém um alto grau de sincopado na clave aguda, sobre o ritmo estável da clave grave (stead). Uma composição ragtime é geralmente composta de três ou quatro seções contrastantes, cada qual com 16 ou 32 compassos de duração.

6 Tradução: "Você já ouviu negros tocar piano de ouvido?...Eles usam o piano exatamente como um banjo. É um bom tocador de banjo, mas não um pianista".

7 Utilizaremos o termo "recursos verticais" para referendar os aspectos relativos à altura das notas musicais. São aspectos que não são basicamente rítmicos (horizontais): são o sistema de afinação, os portamentos, os glissandos, a harmonia e uma série de sonoridades encontradas principalmente na música negra americana, e aqui se evidencia a influência religiosa. Esses aspectos são muito dificeis de serem transcritos no sistema de notação tradicional. É quase impossivel escrever literalmente a interpretação de Ray Charles em Georgia on my mind. No entanto, ainda que isso pudesse ser realizado, seria impossivel interpretá-la de forma semelhante utilizando apenas a partitura e quanto mais detalhada a partitura, maiores as chances de soar falso.

8 Os músicos de jazz sabem utilizar muito bem o piano no blues, buscando efeitos compativeis com os outros instrumentos, como apogiaturas e clusters. Um bom exemplo a ser ouvido é o pianista Jelly Roll Morton (1890-1941), que se auto intitula o inventor do jazz com gravações disponíveis inclusive em piano-roll.

9 Não exatamente no mesmo instante, mas no momento em que tanto o rádio como o disco tornam-se populares e acessíveis à população em geral.

10 A polca foi apresentada no Rio de Janeiro em 1845 e causou um verdadeiro fascínio nas Américas, servindo inicialmente ao gosto da recente classe média surgida da revolução industrial. 0 ritmo em 2/4, em andamento allegretto transmitia uma vivacidade inédita e ao mesmo tempo coerente com a euforia econômica do momento. Essa dança de par unido, como a valsa, era tocada ao piano - um instrumento considerado mais aristocrático naquela época. Ela influenciou outros gêneros musicais provenientes da América do Sul a partir da metade do século XIX, como o choro e o tango. Não se tem certeza de que o ragtime americano tenha recebido essa influência. Não há dúvidas, porém, de que a sincopação desse estilo tenha tido suas raizes na música negra. José Ramos Tinhorão declara que o escritor Machado de Assis, que tinha como tema predileto para suas obras a vida carioca, mais especificamente a das elites e da alta classe média da segunda metade do século, cita a polca em oito de suas obras (TINHORÂ0, 1991, p.59-60).

11 Interesse renovado por certo costume, tendência, estilo de música, de literatura etc. (In: HOUAISS)

12 Conceito baseado na Ontologia. DELEUZE assim entende o território: "0 território é primeiramente a distância critica entre dois seres de mesma espécie: marcar suas distâncias. 0 que é meu é primeiramente minha distância, não possuo senão distâncias. Não quero que me toquem, vou grunhir se entrarem no meu território, coloco placas" (DELEUZE \& GUATARI, 1997, p.127). "0 território é o produto de uma territorialização dos meios e dos ritmos. [...] Ele é construido com aspectos ou porções de meios. Ele comporta em si mesmo um meio exterior, um meio interior, um intermediário, um anexado. Ele tem uma zona interior de domicilio ou de abrigo, uma zona exterior de domínio, limites ou membranas mais ou menos retráteis, zonas intermediárias ou até neutralizadas, reservas ou anexos energéticos. Ele é essencialmente marcado por "índices", e esses indices são pegos de componentes de todos os meios: materiais, produtos orgânicos, estados de membrana ou de pele, fontes de energia, condensados percepção-ação. [...] Há território a partir do momento em que há expressividade do ritmo. (DELEUZE \& GUATARI, 1997, p.120-1).

13 Ações e repetições (ritornelos) dos seres vivos dentro dos territórios que têm dentre outras funções, delinear o território. Por exemplo, os diversos cantos dos pássaros.

14 Outro tipo de ação, o ritornelo do segundo tipo, uma força evasiva que parte de dentro do território para fora dele em busca do desconhecido (a viagem de Colombo).

César Albino é Mestre em Música pelo IA-UNESP, Bacharel em Saxofone e Licenciado em Música (FMCG). Estudou saxofone com Roberto Sion, José Carlos Prandini e Eduardo Pecci no CMBP e CLAM. Possui pós-graduação lato sensu em educação musical, área de concentração-Práticas pedagógicas (FMCG). Leciona improvisação, instrumento e prática de conjunto nos cursos de Bacharelado em Música popular da FMCG. É professor da Escola Técnica do Governo do Estado de São Paulo de Artes (ETEC) e da Escola de Música do Estado de São Paulo (EMESP). Autor dos métodos de saxofone (2003) e flauta transversal (2005) pela editora Gondine.

Sonia Albano é Doutora em Comunicação e Semiótica, área de Artes-PUC-SP; Pós-Doutora em Educação (GEPI-PUCSP); Especialista em interpretação musical e música de câmara (FMCG); Bacharel em Direito (USP); Diretora e coordenadora pedagógica dos Cursos de Graduação e Pós-Graduação da FMCG; Professora do Mestrado e Doutorado em Música do IA-UNESP; pesquisadora do GEPI-PUC/SP; possui várias publicações em anais nacionais e internacionais, revistas, além de livros e coletâneas. 